\title{
Putting Diversity in Perspective: A Critical Cultural Historical Context for Representation in Engineering
}

\section{Dr. Stephen Secules, University of Maryland, College Park}

Stephen received a $\mathrm{PhD}$ in education at the University of Maryland researching engineering education. He has a prior academic and professional background in engineering, having worked professionally as an acoustical engineer. He has taught an introduction to engineering to undergraduate engineers and to practicing K-12 teachers. Stephen's research interests include equity, culture, and the sociocultural dimensions of engineering education. 


\title{
Putting Diversity in Perspective: A Critical Cultural Historical Context for Demographics in Engineering
}

\begin{abstract}
Research in engineering education often takes an orientation which is not anchored in a historical, political, geographical, institutional, or cultural context. Research citing pedagogical best practices are prominent, hypothetically determining the "best practice" for all populations, at all locations, and at all periods in time, past and future. Likewise, many papers focusing solely on the cognitive psychological factors (e.g. self-efficacy, motivation) affecting learning or achievement imply that the cultural norms and interactional/structural contributions to that psychology are either irrelevant or immutable.

This paper takes the view that in order to make wise choices and progress as a discipline, engineering education needs to understand both its culture and its history. By becoming cognizant of and marking cultural practices, we become capable of transgressing or subverting them. By becoming aware of the historical formation of the discipline, we acknowledge the structures which have contributed to our present day culture, and we become attuned to the forces which may be continually shaping us in the present day.

This paper will present a partial historical and cultural account of the formation of engineering as a discipline, its demographic makeup, its narratives and norms. This account is grounded in three engineering educational cultural norms: competition, masculinity, and whiteness. It draws on a combination of work in critical history and Science Technology and Society fields, and the author's literature reviews of engineering education publications. While primarily relying on secondary sources, it is in the combination of the accounts, the connection to present day educational cultural settings, and the communication to a specific audience of educational stakeholders that comprises this work's intellectual contribution.

A prominent theme of the historical narrative is to suggest a reflexive relationship between the demographic representation of the discipline and its cultural normativities. This interrelationship suggests ways in which our deeply held cultural practices may be intrinsically related to our historical and ongoing demographic makeup. This problematizes prominent diversity narratives of which spotlight minority demographic identities in engineering as a novel and isolated concern. It also suggests certain cultural normativities as potential sources of demographic exclusion.
\end{abstract}

\section{Introduction}

In this paper I lay out a partial cultural history of engineering which I believe is relevant to engineering education research and practice. Although the entire paper becomes my argument for the importance of engineering education stakeholders knowing the historical context for 
present-day engineering demographics and culture, I first want to motivate the importance of historical context via the following vignette:

I am attending a business meeting and am right on time. Four out of five of the attendees are present as well, so the meeting begins without the $5^{\text {th }}$ member. Still, 20 minutes into the meeting the $5^{\text {th }}$ member has not arrived and I begin to wonder about the punctuality and commitment of the missing individual. Everyone else was able to make it on time, after all.

After half an hour we receive a phone call on the conference room phone. It is the $5^{\text {th }}$ member, he was never given keycard access to this building the meeting is in and has been locked out. He has been trying furiously for an hour to find someone to let him inside.

In the above story, the absence of the $5^{\text {th }}$ member is the central concern through the first paragraph and remains the relevant fact through the second, but the context of the locked building shifts the perceived meaning of the absence entirely. This says something about the possibility of new information to change the meaning of previously considered objective truths. And although both inferences were true based on the available information at the time, they are not equally valid views with the benefit of hindsight - it is clear that the greater context has enhanced the accuracy of the conclusion. While the original account focuses narrowly on the missing individual, additional details showed the building infrastructure to be an influential contributor. The narrator had experienced the "history" of the meeting up until the point of the phone call, but an incomplete one. The narrator may now feel chastened for the conclusions drawn about the missing individual, and perhaps all the attendees would feel guilty for starting without him. Thus some previously unstated norms and assumptions, or "culture," of the meeting setting may now be implicated in creating the individual's lateness.

At times, engineering education research can tend towards narrow empiricism in this way, to carefully document the data without as carefully uncovering or presenting the relevant context behind the data. In the next sections I lay out what I see as the context we typically take as relevant for diversity work and conversations, address the value and limitations of this context, and make a specific case for the importance of developing the cultural historical context of diversity in engineering.

\section{Our Ordinary Diversity Context}

Many engineering education publications and presentations concerning diversity begin by setting a stage for one or more underrepresentation issues the paper will focus on. Providing some sort of context for thinking about diversity is important: it can inform the shrinking number of readers who remain completely uninformed about under-representation issues, it can clarify certain immutable facts of the subject matter (for readers who may trust a gut intuition that does not correspond to reality), and it can set the stage for a shared understanding which a publication can build off of as it makes a theoretical or empirical case.

Perhaps the quintessential diversity introduction begins with a comparison of representation between the engineering profession and the US working-age population. Though women are over half of the population in the US, they are only $30 \%$ of professional engineers (National Science Foundation, 2013). Underrepresented racial minorities (African American, Latino, etc), 
make up only $13 \%$ of professional engineers, compared to $30 \%$ of the population. Drawing on overall numbers from the national reporting bodies can paint a picture of the size of the diversity problem. The nature of the problem can then be framed in multiple ways: engineering as a position of relative social and economic privilege which is not equally accessible, or engineering as needing a diversity of perspective to reach the best product (Slaton, 2015).

In education-focused work, perhaps from the profession the diversity context moves to the underrepresentation issues as embedded within the engineering education pipeline. Factors related to the retention or attrition of underrepresented groups include curriculum overload, loss of interest, poor teaching, study skills, and a lack of role models (Seymour \& Hewitt, 2000). Quantitative research helps position the educational context as a high leverage player for better or worse in responding to the diversity problem of the profession.

The diversity context might then relate underrepresentation issues to the human scale and note the sorts of marginalizing experiences documented by qualitative researchers listening to students from underrepresented groups (e.g., Danielak, Gupta, \& Elby, 2014; Foor, Walden, \& Trytten, 2007). Or we might tell an anecdote of our own, as a member of an underrepresented group who came up through engineering, or as a person with friends or students or children who have similar experiences. Here we can see the pie charts and p-values play out on the human level, and we can see how human experiences of their own trajectories connect to the net effect. We also get to feel the great emotional toll of the process of an averted educational trajectory. We get to think about elements of dignity and humanity, elements which are impossible to quantify but undergirding many of our motivations and orientations to the issues.

Given how frequently one or more of these are shared to set the stage for presenting diversity work, perhaps these elements make up a collective normative context for our diversity understanding (Figure 1).

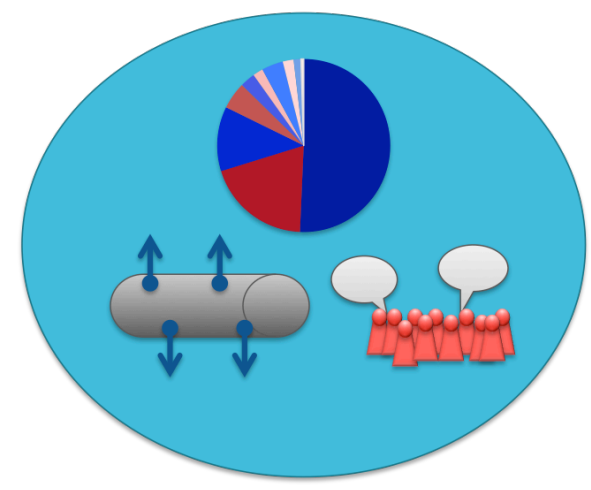

Figure 1. A common diversity context including a pie chart representing representation numbers, a pipeline representing retention factors, and quote bubbles representing the voices of marginalized students from qualitative research or personal experience. 


\section{Affordances and Limitations of Our Ordinary Diversity Context}

Once again, establishing a shared context is critical for productive conversation or work on any topic, including diversity. In addition, this context may represent key components of a collective schema or mental backdrop researchers and practitioners concerned with diversity use to orient themselves and their activities. That is to say, I suggest this is a partial set of the facts which concerned practitioners and researchers are aware of, take as a shared understanding, and reference in conversations about diversity.

In addition to the importance of having $a$ context, there are good reasons for this being the starting place of the diversity conversation. This context proves to be valuable in orienting dayto-day work as a social justice struggle which is far-reaching, interpersonally embedded, and susceptible to change.

Nevertheless, there are some limitations of the ordinary diversity context as I have presented it. Figure 2 presents aspects of diversity which I suggest are typically not as prominently included when the diversity context is laid out in a publication or conversation, but which this paper will argue are highly influential:

- Although the experiences and issues of marginalized groups are affected by and perhaps primarily shaped by the Actions of Dominant Groups, we usually background them in the diversity conversation.

- The aspects inside the circle offer a fairly "present day" snapshot, or chart a few years' worth of progress on representation statistics. The History which has shaped the present day context, particularly the history before the days of diversity statistics, are comparably less prominent in the diversity conversation.

- Although qualitative research on marginalization does implicate a chilly climate or competitive educational Culture (e.g., Foor et al., 2007; e.g., Hughes, 2012), comparably little is done to critically analyze engineering culture or engineering educational culture to understand how it may be reproducing and shaping experiences.

- In an ordinary diversity context, the fundamental Nature of Engineering is seen as relatively static and unimplicated, and is seen as apolitical and predating the demographic representation issues, rather than contestable and intimately connected to demographic representation. 


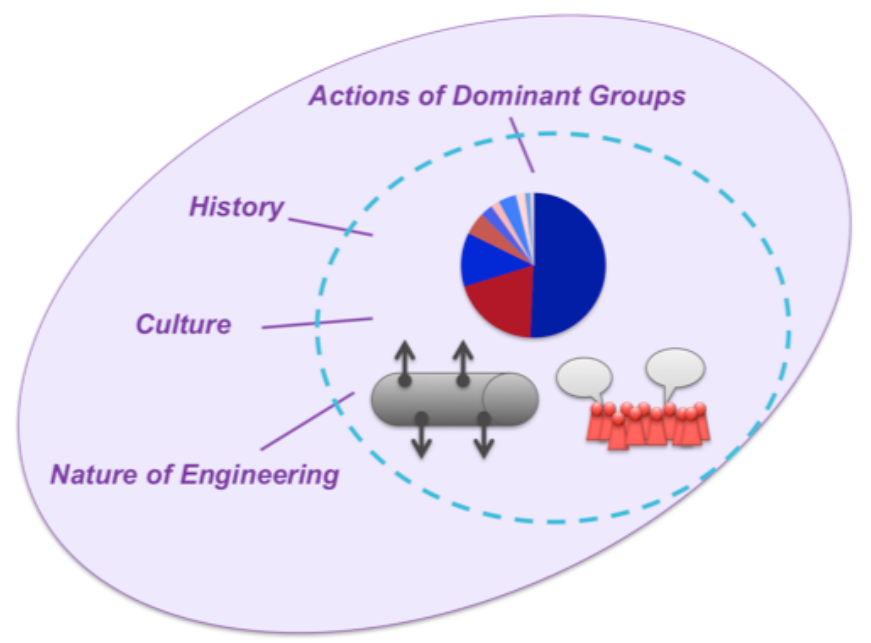

Figure 2: The Diversity Context should incorporate History, Culture, Nature of Engineering, and Actions of Dominant Groups.

This paper will attempt to provide a context which critically examines the cultural history of engineering, including its fundamental nature and the actions of dominant groups of engineering stakeholders. It is my hope that in speaking to the ordinary diversity context I believe many of us (including myself) have started from, this paper can provide an initial impetus for shifting towards a more nuanced context for our work. In particular, the paper will present what seems to be some lesser-known history of the engineering discipline, highlighting the role dominant groups and disciplinary norms have played in forming and perpetuating the demographic representation realities of the present day.

\section{The Case for Historical Context}

Both the engineering discipline and the field of education research can have a present day datadriven orientation, so perhaps it is not surprising that the norm is particularly strong in engineering education. Frequent papers for example which promote pedagogical "best practices" and generalizable psychological factors background the geographical, historical, interpersonal, and cultural context of engineering education. In contrast, a more limited number of historical accounts have appeared in the engineering education literature, for example, noting the progression of certain pedagogical debates (Seely, 1999) and particular noteworthy historical case studies (Wisnioski, 2014).

In the story about the meeting, a lack of proper historical context resulted in blame for the individual whom was actually the victim of the building infrastructure problem. Likewise, an ahistorical and uncritical diversity context is susceptible to victim-blaming as well. The warped reasoning goes, if engineering is a purely technical discipline in which women and racial minority groups struggle to find representation, perhaps the problem is in the motivation or intellectual capacity of those individuals themselves. This deficit view may not be held by many readers of this paper, but will inevitably be held by some consumers of the diversity context presentation when viewed in isolation (for example, a recent bizarro-world Breitbart article titled "Here's Why There Ought to Be a Cap on Women Studying Science and Maths" repurposed underrepresentation statistics to argue for decreasing supports for women in STEM, who have proven by now they don't deserve it). While researchers take many approaches to counteract 
deficit views, it is my view and hope that historical context provides a more fundamental refutation.

Just as context shifted the interpretation of the meaning of the story about the meeting, so does it shift the context of the demographic representation in engineering towards greater accuracy. This is not a relativistic scenario with two equally valid interpretations, but a case where historical context provides the crucial additional information necessary to understand the present.

\section{Methodological Approach}

The methodological approach behind this paper draws on several secondary sources which reveal a new context for diversity. Thus the historical research presented is not my own, but is cited and synthesized here for relevance to an education-focused audience. The literature bodies investigated were largely Science Technology and Society and critical history scholarship. In places, I conduct my own literature reviews of prominent engineering education publications (e.g., Journal of Engineering Education, National Academy of Engineering). In that I drew on several disparate literatures this work was necessarily less systematic and more idiosyncratic than is a traditional literature review methodology. It grew out of conversations and reading suggestions from several colleagues, and represented a learning experience for myself (an engineer by prior profession and educational ethnographer by current vocation) as well.

This work has resonance with a methodology outlined by Foucault (1977) called "history of the present," or historicizing, where the cultural historical context for present day events is interrogated to shift and enhance an understanding of present-day meaning. Foucault's historicizing has been applied in science education by Kirchgasler (2016) to situate the discussions of diversity in the NGSS standards.

\section{Emergent Cultural Themes}

This historical account focuses around three particular cultural themes: masculinity, whiteness, and competition. There were several reasons for the choice to center these three cultural norms. First, these cultural norms emerged out of and were identified in the author's prior ethnographic work on engineering educational settings (Secules, Gupta, \& Elby, 2016), and were implicated in the construction of classroom-based marginalization. Other ethnographers of engineering education have also noted the prominence and impact of masculinity/gender (Foor et al., 2007; Pawley, 2008; Tonso, 1996, 2006), meritocracy/competition (Foor et al., 2007; O'Connor, Peck, Cafarella, \& McWilliams, 2016; Stevens, Amos, Jocuns, \& Garrison, 2007), and whiteness/racial normativity (Battey \& Leyva, 2016; Foor et al., 2007). Finally, these three themes seemed perhaps an uncontroversial starting place for insiders to engineering education; I hoped that various stakeholders would be able to basically agree that engineering exhibited these three norms, even if they might struggle to define or explain them, or might not know why they exist. This agreement lends support to seeing these three as cultural norms in engineering education, and engineering more broadly.

\section{A Critical Cultural Historical Context for Representation in Engineering.}

The following subsections each develop a component of the historical context for diversity in engineering. This account does not claim to be exhaustive in determining the cultural and 
historical influences on engineering; I have specifically chosen the narrow topic of a historical context for demography and culture, which is seldom explored in the education literature (except by those cited below, and similar). It is meant to be a resource to point towards what may be lesser known research on this subject, a starting point for synthesizing across smaller studies to a sense of a historical context for diversity in engineering, and a call to others for resources and perspectives to the developing historical context.

\section{Defining Engineering and the "Other"}

There is a simple story we tell ourselves about engineering. A US national culture story, and an engineering story. Engineering is the quintessential productive force behind the industrial revolution. A modern invention, a capitalistic invention. It thrives in a capitalistic democracy such as the US. Engineering is rational and technical. As such it escapes the worst injustices of US history. It has little to do with racism and sexism; is quintessentially colorblind and classblind and gender-blind - it just happens to be occupied consistently by middle-class straight White able-bodied men. It has driven American economic growth towards exceptionalism and domination, and conversely it has not been responsible for any of its setbacks. How can this be? It must be, so goes the narrative.

In Making Technology Masculine, Ruth Oldenziel has suggested the narrative for women in technology and engineering is as "deae ex machina" ("goddesses out of the machine," Oldenziel, 1999 , p. 18)-- as a relatively novel phenomenon of women succeeding in a fundamentally maledominated discipline, springing forth fresh in the late 20th century from 2 nd wave feminism and affirmative action, without having been a concern at any prior period. This unexplained arrival via attention to affirmative action statistics applies equally well to racial minorities and other minority groups of recent concern. ${ }^{1}$ Thus the historical account of demographic representation seems to start at the point when the engineering discipline collectively began to notice and care about minority groups (Lucena, 2000).

Another common engineering narrative is the disembodied nature of the engineering discipline as a body of knowledge. We are clear that engineering is a knowledge domain and an identity navigated within a community of practice (Stevens, O'Connor, Garrison, Jocuns, \& Amo, 2008). Engineering as a subject matter clearly delineates the population as those who participate within it (as students, professionals) and those who do not. This delineation includes certain epistemological continuities (e.g. using math and science to solve real world problems), as well as institutional legitimation, industrial and commercial interest, professional licensure, etc. But if engineering defines engineers and non-engineers, who has defined engineering? Who collectively has defined it in the past such that it is an "always already there" of our present day? Whose actions (intentional and unintentional) continue to define engineering in the present day?

In short, the disembodied engineering and arriving deae ex machina narratives are flawed. Engineering is not a white, male, middle class, straight American discipline by happenstance. It

${ }^{1}$ I am choosing to link various diversity concerns in this paper in order to show continuity between the forces which shaped the gender, racial, socioeconomic, and cultural norms and narratives of the discipline. 
shares much of its history with mainstream American professional life, a history and culture which is often observed to be racist, sexist, classist, etc. Even simply tying the engineering discipline to these forces of oppression is a disruption of the simple engineering story-troubling an important part of the narrative that engineering is purely technical, disembodied, and therefore free from any of the interpersonal "isms" and disconnected from US historical events such as slavery, Jim Crow social control, class abuse, and forces (e.g. anti-suffragist) which kept women in their place. Furthermore, engineering predominantly and in particular carries a deep set of power dynamics in its demographic representation and cultural norms that has a more complex relationship than its ties to oppressive US demographic trends in general. The definition of engineering disciplinary knowledge and practice was not and is not disembodied or arbitrary, but directly related to social positioning and power (Foucault, 1982). Those who held relative social power and specific power in the institutions associated with engineering defined engineering, and they defined it in order to secure and consolidate power. As the next section will elaborate, social exclusion and domination in engineering have always been fundamentally inseparable from other disciplinary features.

\section{The Professional Formation Work of White Middle-Class Men}

The word "technology" first appeared in the early 19th century and gained prominence over the course of the 19th century (Oldenziel, 1999). The invention of the words "technology" and "engineering" marked a process of active boundary formation between old ways and new ways of organizing labor and industry. The older term, "the useful arts" conjured a different image for the activities that would later come to be known as technology and engineering (Oldenziel, 2006). The "useful arts" emphasized craftsmanship over the systemasticity that engineering as "applied science" invoked, and learning the useful arts conjured an image of an apprentice in a trade over formal educational requirements which were being put in place as engineering training. Notably with regards to our central question about the demographics of the discipline, the useful arts also applied to a wider range of industries, including cooking and textiles, whereas engineering would come to be associated narrowly with steam engines and boiler rooms. In the strictly divided gender roles of the time, whereas the world of "useful arts" was a gender inclusive term, the term engineering referred to settings which were almost entirely off limits to women.

Thus vocabulary was but one piece, a definitional boundary piece (Klein, 1996; Pawley, 2008), of the active work of demographic exclusion in the discipline of engineering. Although the defining term united the engineering discipline in opposition to other work, its professional formation was also driven by disparate and interwoven industrial, labor, governmental, and academic forces shaping the character of activities of civil, mechanical, chemical, electrical, and other branches of engineering (Zussman, 1985, p. 4). In general, over the course of a few decades, engineering became a discipline which required a formal education, and spurred the creation of engineering departments. Activities like the building of buildings that had for centuries been learned as apprenticeship in craftsman tradition (think of the architectural and structural wonders of the ancient world), now became formalized as structural engineering. A separation was created between the building work and manual labor (skilled or unskilled) involved with the creation of technology and the built environment on the one hand, and the now rarefied discipline of the engineers designing the technology (Oldenziel, 1999; Zussman, 1985). 
Viewed through a certain lens then, the events of the late 19th and early 20th century look like an inadvertent realignment: a shift from a gender neutral discipline towards a masculine one, a shift from a term associated with unskilled labor to one associated with elite higher education. But the STS narrative for professional formation argues that this should not be viewed as an accidental realignment, but as the active boundary work that white, middle-class, collegeeducated men performed in order to secure a social and economic position (Oldenziel, 1999; Wajcman, 2006). Consider the relative upheaval that democracy, capitalism, and the industrial revolution were posing at the late 19th and early 20th century Consider the rising trend of Marxist revolt in the labor classes. Indeed, consider how threatening abolition and the extension of voting and other civil rights (to women, to unpropertied White men, to African Americans during the brief window of Reconstruction) must have been (Roediger, 2007). More than an inadvertent realignment or the pressures of market forces, middle class White male engineers carved out a role for themselves in a new economy and social order.

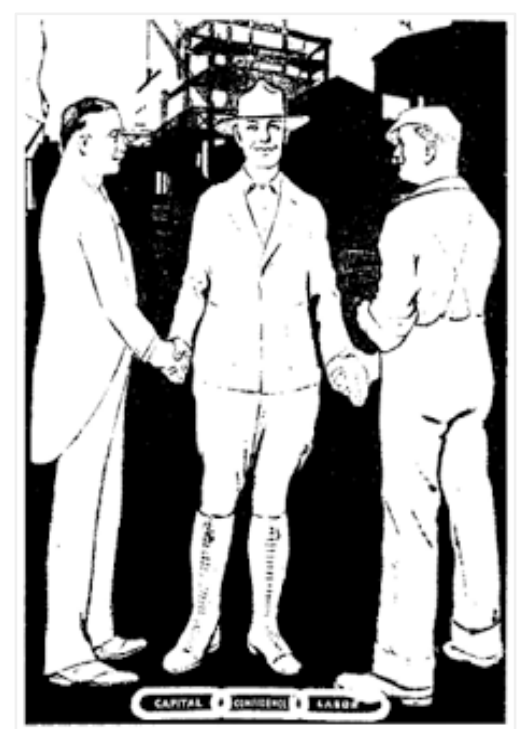

Figure 3: Engineering propaganda showing an engineer as a vital link between symbolic capital and labor (Oldenziel, 1999, p. 75)

The White middle-class professions were a relatively new invention of the time, and it was a position they still needed to secure to establish social status (Zussman, 1985). As such, engineers undertook the active work to justify a position for themselves between Labor and Capital, as Figure 3 above (Oldenziel, 1999, p. 75) shows (published in 1924 in The Professional Engineer). The engineer in the image is easily identified by readers at the time by the professional uniform of the site engineer, and it should not seem accidental that all characters in this scene, including the Engineer, are White men. This and other professional propaganda of the time were part of the active work to secure a social and professional position for those individuals forging an identity as engineers.

\section{Racialized Social Control and Exclusion in Engineering}

The sphere of technology and engineering was bourgeoning (slowly, or in fits) across the globe throughout the 19th century. The industrial revolution in the late 19th century also coincided with a great social upheaval specific to the US-- abolition. In these ways, slavery comes to be associated with antiquated industries, and engineering comes to be seen as modern. But just as 
the recovery of the term the useful arts showed us the continuity and boundary work of industry before and after redefinition, this is as much a fabrication and utilitarian narrative as it is a reality. The industrial work of the pre-abolition period was agriculture, mining, manufacturing-these are the same industries which were growing to be considered engineering over the course of the century. Engineering is tied to the history and growth of US capitalism, and one argument that slavery was not profitable and the capitalist industrial revolution overtook it positions engineering industry as simply a more efficiently organized form of capitalism. Considering the counter-argument - that slavery was in fact highly profitable for those who used up Black lives, and could only be ended by a war of competing interests (Baptist, 2014; Williams, 1964) —one wonders if western engineering and technology developed partially (or at least regionally) because of the lack of a free labor force.

But abolition did not end racialized social control in this country, nor did it end the profitability of using a free labor source (Alexander, 2010). After a period of Reconstruction, Southern whites inflicted a sweeping set of social controls which turned back progress to something akin to slavery. They stripped land owning rights, and made blacks beholden to the whims of a White plantation owner, working the land as sharecroppers to return a small piece of profits. They stripped away nearly all civil rights-- voting rights, jury service, public office-- often through subtle means that limited the public appearance of racism, for example a literacy test and poll tax could prevent essentially all blacks from voting, while a grandfather clause allowed poor and illiterate whites to continue to vote. Insidiously, by removing legal rights, blacks could essentially be accused of any minor or fraudulent infraction and acquired for the purpose of profitable manual labor in all of the industries which had suffered since pre-abolition. Between the roles of share-cropping and prison labor, some form of forced labor was essentially still a life sentence.

Systems of mass leasing of Black prisoners became an open secret across the south (Blackmon, 2009). Prison camps and sharecroppers once again produced agricultural wealth in the south. Fueled by the industrial revolution, prison camps became heavily involved in the work of mining and production of natural resources such as timber, copper, lime, and steel. This process of profitable, industrial racial social control is not ancient history; it continued from the 1860s period of abolition nearly uninterrupted by any significant government sanctions well into the 20th century (Myers \& Massey, 1991). The last prison mines were finally outlawed by FDR in the 1940s directly after the bombing of Pearl Harbor, arguably because of the embarrassment it might have caused in fighting a war of moral superiority on race issues (Blackmon, 2009). It is also not a minor or exclusively southern history, as it implicates US Steel (an amalgamation which included Carnegie's famous steel corporation). It appears to be a fundamentally US national, industrial, and capitalist corporate history.

When considering the burgeoning industrial interests in mining and natural resources, a nascent engineering springs forth from the prison labor accounts: mining engineering, agricultural engineering, civil engineering of railroads-- the engineering fields which defined the nature of labor-- as well as mechanical engineering, electrical engineering-- the fields which created such an imminent demand for free labor. Advances in mining lime kiln were still incredibly dangerous for workers, consistently killing or maiming workers (Blackmon, 2009). One of the byproducts of prisoner camps as opposed to slavery was that the worker was not valued property, but a cog in an industrial system and an individual swept up and out of society; the cost of 
leasing a prisoner plummeted compared to the prior cost of owning a slave. So the system in which mining was enacted, and engineered, at the time and in the region was without regard for the life of the worker. Mortality rates were often up to $20 \%$ per year. The work of the mines was engineering, and a technological advance, but the human lives of Black prisoners were not regarded in the calculus. US corporations (e.g. US Steel) we typically think of as fundamental success stories of American capitalism and engineering industrialism have inherited the profits of this process we obscure and divorce from those stories and do not see as reverberating in the present day.

When overlaying the historical narratives of engineering professional formation (Oldenziel, 1999) and racialized forced labor (Blackmon, 2009) I see a group of White middle-class men who have taken social control by defining and defending a new social position: the engineer. White engineers, White corporations, and White paid industrial laborers set out to profit in the ways opened up by the industrial revolution and new forms of industry (Oldenziel, 1999; Roediger, 2007). Although a few notable exceptions of Black men were able to make progress in inventive work (Wharton, 1992, pp. 1-20), by and large Black workers were not only prevented from sharing in the social position and wealth accumulation of White engineers, but they were used-- their collective forced labor and literally their lives-- were used for the political and social gains of American middle and upper class White men in engineering enterprises. American engineering is fundamentally connected to capitalist industry, and many capitalist histories may look like the use and abuse of a certain group for the profit if examined in a certain light. In addition, American history and American industry have a prominent strain of perpetuating White supremacy. It is perhaps unsurprising that pulling on a thread from America's engineering industrial past reveals ties to racial abuse and profiteering.

And yet, as an engineer this history of my tradition weighs heavy on me. Perhaps this little known origin story contains a parable for our modern conceptions of engineering: it is always a practical reality within the work of engineering that we prioritize certain stakeholders in the scope of work, without equally considering every and all possible stakeholders on which the task may have effect. Within that process it is possible to ignore the stakeholders who are culturally distant, or devalued as less human. Should we see grueling and life-threatening mining processes as embodying and perpetuating racial oppression? To what extent have we maintained the use and abuse of working class / people of color within the design of the engineering processes they labor in? To what extent do the client and end user benefiting from engineering work continue to be predominantly White people? To what extent have we retained or shifted the category of stakeholders (racial minorities, low socioeconomic status, undocumented and overseas populations, animals, the environment) whose use and abuse we ignore for the profit of others?

\section{Engineering Education: Separate But Not Equal}

Another prominent way in which engineering should be seen as having a relationship with racial oppression is through unequal educational access. In the US, the doctrine of "separate but equal" speaks to a particular rationale for racial segregation during the Jim Crow era. Justified by the Supreme Court during the case of Plessy vs Ferguson, it had ramifications throughout nearly all aspects of society, from swimming pools to public transportation to educational institutions. What is commonly understood from this period is that "separate but equal" was in practice in almost every case a myth White society told itself in order to justify the propagation of unequal and lesser provisions for the Black population. The 1950s Brown vs Board of Education decision 
reversing Plessy vs Ferguson is memorable as the key event in the end of racial segregation of public schools in Jim Crow era. But even engineering educators familiar with this history might nonetheless be surprised that engineering education was a fundamental player in propagating "separate but equal" policies and myths, that engineering education was uniquely resistant among professions to recognizing the inevitability of integration. And that the ripples of this protracted period of systematic racial exclusion are the relatively recent backdrop that modern day affirmative action initiatives should be seen as responding to.

Amy Slaton (2010b) provides a revealing account of the University of Maryland from the 1930s to the 1970s. During this period, UMD, a land grant institution received particular benefits from the federal government and the state of Maryland, and in return assumed certain responsibilities to educate the public and conduct research for the benefit of society (in particular, originally related to agricultural science). In the Jim Crow era, any higher education institution which received this level of public funding was required to maintain a "separate but equal" companion school for the Black population. In Maryland this was Princess Anne College (later University of Maryland Eastern Shore). As with most of the segregation schemes of the era, Princess Anne was poorly funded, never fully staffed with qualified personnel, and never had proper investment in infrastructure. Parallel to the public education enterprise, the inequality of the system was propagated by racist and intransigent stakeholders and justified through various legal loopholes and racist cultural assumptions.

One particular aspect of inequality between the two systems was access to professional training in specific career paths. In the 1930s, this was brought to the fore by a legal challenge to the UMD law school in Baltimore. The result of this legal challenge was a new separate-but-(more)equal law school at Morgan State. The legal ramifications of this precedent were clear-a White institution which received public funding would now be required to maintain equality for the companion Black institution in the dimension of each individual subject matter offered. In spite of this obvious logic and receiving pressure from the local NAACP and others, UMD's College Park campus and its prominent engineering professional school resisted correcting either their admission policy or their funding, staffing, and infrastructure deficiencies in Princess Anne-- for the next four decades, past the famous 1950s Brown vs Board decision, and into the 1970s (Slaton, 2010a). Not only does engineering education have a particular relationship with our national histories of education segregation, it can be seen to be uniquely resistant to progress. The struggle for equal educational access for engineers in the UMD system parallels similar struggles to gain access at other universities, David Wharton (1992, pp. 33-80) details similar struggles at Howard, MIT, Hampton Insitute, etc.

The UMD engineering department's close ties to meritocratic allotment of military and industrial research funds exacerbated the inequality. As the College Park campus grew and prospered in their position at the cutting edge of science and engineering knowledge, the Princess Anne campus continued to offer only subject matter effectively towards becoming a polite and obedient agricultural worker. One of the collective myths put forth by many southern segregated engineering departments was that not enough Black individuals were qualified and interested in engineering to justify offering the subject matter, and any individuals who were could simply attend Howard University (i.e., the one HBCU that had attained an engineering department). This last point shows how engineering meritocracy and a racist cultural view towards Black 
engineering students' potential justified and perpetuated a structural inequity which provided self-serving evidence for this view for decades.

\section{Normative Preservation of Engineering Masculinity}

Around the turn of the 20th century there were clear structural barriers and cultural norms against women participating in the discipline of engineering. Women were not admitted to study engineering, they were not given jobs in engineering, they were constrained from all but a very few professions-- (e.g. seamstress, midwife). The solving of problems in the domestic domain, namely home economics, was given a subordinate gendered role in educational institutions (Bix, 2002; Pawley, 2008). But the structural barriers were contested comparatively early on (e.g., by early female engineers who in spite of being ignored and unsupported made technological advances and a strong case for their own importance in the field), and the events of World War II and the 1960s protests brought strides, albeit contested, for available educational and professional options for female engineers (Bix, 2000; Oldenziel, 2000). Over the 20th century, however, cultural norms perhaps came to dominate the forces working for gender exclusion. Even when included in the engineering profession or engineering education, women were consistently marked and marginalized as "Engineeressess" or "Girl Engineers" (Bix, 2004). Engineering seemed by definition to require a particular masculinity in order to do it properly-engineering mixed a shop floor working class masculinity with a rarefied higher-educated middle-class masculinity (Oldenziel, 1999). In the role of the industrial shop floor manager, masculinity and class identity allowed the engineer to sit (or purport to sit) between the two forces it had defined its role as linking (Oldenziel, 1999, p. 75).

In addition, the engineering discipline arguably inscribes gender into its technologies and tools (Wajcman, 1991; for similar arguments related to science see Noble, 1992). If men are doing the work of engineering, and men are culturally permitted to get dirty during their work and (at times) physically predisposed to lift heavier equipment, then men can design their engineering tools to require being dirty and lifting heavy objects. This effectively prevents women from engaging within the profession, since it would be cultural impermissible to do so. If women had been involved in the profession from the start, the cleanliness and physical accessibility of tools would have been engaged with from the start, and several engineering processes may have looked drastically different. Parallel arguments can be found related to physical disability-- when people with physical disabilities are marginalized from society and the collective design process, the things we use are designed so that these people are disenfranchised, thus normative culture is synonymous with disability (McDermott \& Varenne, 1995). In cases of a large enough disabled population or a carefully integrated disabled stakeholder is appealed to, systems are designed which normalize and assist people with and without disabilities (e.g., the sizeable deaf population in colonial Martha's Vineyard, McDermott \& Varenne, 1995, p. 328). In the progression of the engineering discipline, initial explicit structural exclusions based around gender gave way to a set of more hidden cultural norms which continued the effect of gendered exclusion and subordination for several decades.

The inscription of gender into engineering practices suggests a relationship to a broader theory of the sociology of gender. The theory of homosociality from the sociology of gender argues that several norms of a discipline may relate less to intrinsic aspects of the discipline, and more to the maintenance of male participants (Bird, 2016; Lipman-Blumen, 2016). As a limited social theory, this scholarship positions itself as an explanatory theory for the patterns in several 
masculine-dominated disciplines, without presuming to be exhaustively predictive for all settings. The theory goes: men enjoy interacting with other men, and their interactions and cultural norms can function to preserve masculine exclusivity. This enjoyment is non-erotic, and primarily conceptualized as a force among dominant/hegemonic masculinities (so "effeminate" or homosexual masculinities may be suppressed or excluded by the activities, similar to femininities). Thus, disciplines which are more masculine have a tendency towards certain features: including more individuality, more emotional detachment, more heteronormative sexualization of interactions, and more competition and competitive interactions. These features can function in real time as an inclusion mechanism for dominant masculinity and an exclusion of femininity (and non-dominant masculinity).

If many of the above features of homosocial masculinity resonate with our associations with engineering workplaces and educational settings, perhaps none more so than the subject of the final section: competition.

\section{Engineering as A Grand Meritocratic Technocratic Competition}

Several voices have named and critiqued meritocracy and competition as a value in areas related to engineering education. Frehill (2004) points to a historical vision for the formation of professional engineers where proving manhood was intimately tied to the early origins of the modern "weed out" process. Emphasis on endurance, physical vigor, and academic rigor drew on militarized and masculinized images to reinforce a particular sense of engineering meritocracy. Slaton (2010b) argues that it is the engineering discipline's particular cultural values of meritocracy (promoting the best of the best) and technocracy (caring only about results/products and not who does the work) which entrenches its opposition to racial progress and blinds it to its own role in perpetuating a racial hierarchy. She further argues that this cultural framework continued to have effects throughout the progression of the 20th century and up until the present day.

Likewise, In engineering's technocratic meritocracy, diversity initiatives are seen as peripheral to the work of the engineering department (Slaton, 2015). They do not shift content and do not attempt to disrupt any of the dominant groups of the engineering department. Instead they work only at the margins of engineering departments to promote only the "best and the brightest" from underrepresented groups. The lack of an acknowledged engineering origin story of demographic exclusion may contribute to this half-hearted attempt at inclusive reform, resulting in slow demographic progress instead of systemic change.

McDermott makes similar comments about the culture of education in the US. He argues that the American ingrained cultural value of meritocracy fuels the construction of success and corresponding failure in everyday classroom interactions (Varenne \& McDermott, 1999). Education as constructing failure appears to hold explanatory power in engineering undergraduate classrooms as well (Secules et al., 2016). How does the engineering context extend McDermott's arguments for the principle meritocratic function of US school? The technocratic, product-focus Slaton has highlighted may provide one answer.

In addition, a critique of the culture of competition particularly in education came during the late 20th century (Kohn, 1992). Kohn argued a distinction can be made between structural competition (activities construed as mutually exclusive goal attainment), and intentional 
competition (a personal orientation towards competition in interactions and mindsets). Structural competitions can sometimes emerge from a scarcity of resources, and in other cases can simply be in order to pursue a prize or recognition. Even in the sense of a scarcity of resources, a structural competition is a specific choice to enact, since there other frames (cooperation, individual-but-not-competitive work) which are possible even within scarcity. On the other hand, intentional competition is something which can be undertaken whether or not a structural competition has been enacted (e.g. when a person wants to make even the simplest activity into a race). Kohn sparked a conversation on these forms of competition as mutually interlinked and far from being inevitable, they are in fact undesirable forms of structure and interaction for many aspects of productivity, learning, affect, interpersonal community, and even ethical behavior. Kohn (and McDermott, e.g. "kill thy neighbor" game (Varenne \& McDermott, 1999) ) sparked a conversation in 1990s K-12 education where many considered whether other non-competitive structures and interactions were possible and desirable. Although influential in K-12 education research, neither McDermott nor Kohn have been cited in the Journal of Engineering Education.

So engineering education seemingly missed the conversation and the opportunity to reflect on the value of competition in its pedagogy and culture. Thus exploring the element of engineering culture as competitive is more challenging to do in a historical review. Competition is something many in engineering education would acknowledge, in many meanings of the word, yet few would feel the need to question, problematize, or even document it. Indeed, it seems few have: I have not found incisive historical ethnographic accounts of the development of competition or competitiveness in educational or professional settings to the same extent as other cultural and structural features. Several meanings of "competitive" conjured in the literature are distinct, overlapping, and mutually interrelated. This section will explore the contours and development of competition and competitive culture in engineering education, to the extent possible through the current methodology. To make my point, I often draw on journal articles and national documents, noting what they say, and what they don't, about competition.

\section{The Many Unexamined "Competitions" of Engineering}

One way in which engineering is competitive relates to the concept of a discipline deeply embedded in a capitalist industrial marketplace. Publications which set out a national agenda for engineering frequently appeal to the need for U.S. engineering to respond to "stiff competition" (ASEE Task Force, 1987, p. 7) and for U.S. engineers to maintain their "competitive edge" (National Academy of Engineering, 2004, p. 41). This grounding of engineering education within capitalistic competitive frames is potentially not the only available framing one can take for professional vision (e.g., the less capitalistic emphasis in human-centered design, Engineers Without Borders), but it is a reasonably logical one. These sorts of imperatives are felt, responded to, and revoiced by individual industries and corporations, who are seen as primary partners and stakeholders in engineering education.

Competitive national and industrial pressures filter into educational standards and priorities (Deboer, 1991; Lucena, 2005). They also shape pedagogical choices, where specific courses are developed to meet needs for industrial competitiveness (Dutson, Todd, Magleby, \& Sorensen, 1997; Todd, Sorensen, \& Magleby, 1993). One industry-based Council on Competitiveness once concluded with pronouncements for education such as: "We can only obtain a long-term competitive advantage by learning faster than the rest of the world" and "Product development is the next competitive battle ground" (Frey, Smith, \& Bellinger, 2000). Re-thinking Engineering 
Education (Crawley, Malmqvist, Östlund, \& Brodeur, 2014), a prominent agenda-setting document, seems also to use language which elides industrial competitiveness and authenticity with pedagogical structured competition "Courses based on competitions have aspects of designbuild-compete." The industrial resonance of the phrase "design-build" seems to imply that competition in education will prepare oneself for competition in industry " (Crawley et al., 2014, p. 102). As is typical in the literature, the structured course competition here is mentioned as a simple description of pedagogical programming, not particularly explaining or interrogating the role of competition as worthy or productive. The similarity in phrasing and the lack of parsing a distinction in different "competitions" suggests how a link may be commonly inferred-- the engineering international and industrial marketplace is and must be "competitive," so the way to prepare engineers is to have them "compete." I question the simplicity of this elision, as the scales of and experiences of competition in these two senses-- an industrial capitalist competition offline between countries or companies, and a head-to-head student-to-student competition based on timeliness and effectiveness of solutions-- are quite different. If in some sense we need the engineering industry to be "competitive" it may not follow that we need to educate students via "competition."

A simple and common way that pedagogical competition is discussed is to contrast it with paperbased pedagogy. The Re-thinking Engineering Education publication continues, "In contrast with traditional 'paper' design courses, the essential feature of such experiences is that students actually build the design and verify its effectiveness" (Crawley et al., 2014, p. 102). This is a commonly explored dichotomy and tradeoff. On the one hand, industrial interests suggest a need for training in solving real world problems which is delivered as problem-based learning principally conceptualized as a design competition. On the other hand, research funding interests present a need for conceptual knowledge which are principally delivered as textbook learning in engineering science. For example, this dichotomy of education via textbook engineering science or industrial project is examined within one prominent history of engineering education (Seely, 1999). Competition does not, however, represent the opposite of textbooks. There are several available active learning participation frames that are more collaborative or non-evaluative in nature. As support for these alternative frames, a study on the affordances of active learning in its different forms (Prince, 2004) concluded that collaborative and cooperative learning environments in engineering result in more learning than (individually) competitive environments. Unexplored within this scope of research is a reality that many of the collaborative and cooperative active learning environments in present day engineering education are actually nested within and framed as grand competitions, and that even classroom events without a competition framing often take up competitive interpersonal interactions (Secules et al., 2016). When other disciplines (e.g., my $\mathrm{PhD}$ home department of education) enlist students in a collaborative learning activity, they rarely conduct it as a competition.

Another common rendering of competition is as a motivator, as a form of being responsive to student interests and letting students have fun. Yet we also know from literature that not everyone is enjoying their education as a perpetual competition: the diversity in engineering literature has frequent mentions of "competitive culture" as an aspect which alienates women and leads them to leave (Foor et al., 2007; Seymour \& Hewitt, 2000). This form of competition may also refer to competition in a meritocracy, competition for a scarcity of grades and positions-- yet the idea of engineering courses as consistently competitive in both interaction and in structure seems plausibly at play as well. Yet even when posited as a cause for a lack of 
gender diversity, competition has not come under much deep scrutiny. Perhaps it is the way in which the engineering discipline views competition as a fundamental cultural norm, so fundamental that it cannot be seen or lamented, that has prevented further analysis of this aspect of ourselves.

\section{Culture and Demography}

We know from history that certain disciplines have maintained certain gender norms over time, and that others have shifted. Computer programming was originally a women's discipline, seen as lowly and technical work. Over a short time, the intellectual demands of the discipline did not change, but the gender representation in the discipline did, as did the esteem and pay for the discipline (Ensmenger, 2010). It is now a male-dominated field, famous for its head-to-head hack-a-thons to compete for positions. Education went from a man's discipline to a woman's, and became a field less intended for the brilliant individual, less esteemed, more associated with caring, and less associated with individual brilliance ("those who can do, those who can't teach.")

Engineering has had no such shifts. We know engineering is a White and masculine discipline because of historical formation, social control, and educational exclusion. We know that certain normativities (dirtiness, physical demands) maintained the normative masculinity throughout the past century. If competition is a known masculine homosocial normativity, is it a force perpetuating masculine engineering demographics? Is engineering competitive because it is authentic to the requirements of the discipline and a pedagogical good? Or, is engineering mysteriously competitive in part simply because it is occupied by White men? And, could it be intransigently masculine because it is competitive? If so, what other of our engineering disciplinary features have we inherited with the historical baggage of masculinity and whiteness?

\section{Implications}

\section{Taking Stock of the Historical Account}

I motivated this historical account by positioning a standard diversity context which seemed grounded in the present day, focused on marginalized populations, and which held a static view of engineering culture and disciplinary practices. Having elaborated a historical context which integrates these aspects, I return to the idea of presenting a context for underrepresented groups in engineering. In this preliminary new historical context (Figure 2 and the content of this paper) we retain awareness of present-day representation and experiential realities of marginalization, while integrating the salient influences of culture, history, and engineering disciplinary practices and culture. With this framework we may attain a greater precision and accuracy for presenting facts about underrepresentation in present-day engineering, facts which are subject to shifting when presented with a new context.

As a historical account this paper makes intellectual progress in two significant ways. First, it promotes intellectual cross-pollination between STS and historical communities and engineering education, spurring a new conversation around the implications of broader historical context for present day stakeholders. Second, it presents several areas which due to the depth of the primary historical accounts are often analyzed and presented as somewhat distinct: masculinity/gender, whiteness/race, meritocracy/competition, educational access, pedagogy, professional norms, 
disciplinary boundary formation, etc. This historical account presents these forces as overlapping and at times mutually reinforcing one another.

It is my hope that the paper has provided some little-known historical context to engineering educational stakeholders, that these facets may be surprising and shift our thinking about our position in the discipline, and that perhaps a new awareness of our culture and history will enable us to subvert and transcend it.

\section{Contributions to Research and Practice}

I see qualitative education researchers and particularly educational ethnographers as potential benefactors of this enhanced historical context. Qualitative researchers are broadly engaged in providing accurate descriptive accounts of educational settings, and ethnographers in particular are concerned with identifying and examining present day cultural norms. If a historical social context can shift the meaning of classroom events, it is critical for qualitative researchers to become aware of it for the sharpening of their own instruments of observation, and then to have the option of revealing (or not revealing) the historical context to their reader depending on their purpose. Ethnographers will have a particular predisposition to wanting to understand and communicate about the context and culture relevant to their research subject. The more we in qualitative and ethnographic education research explore connections with history and culture, the more powerful and accurate our accounts will become.

Appropriate historical context may also shift views of instructors and other engineering education stakeholders. Diversity research and intervention in engineering is often focused on encouraging non-deficit views among engineering instructors. In potential service of this project, I imagine it becomes harder to maintain deficit or patronizing views of marginalized individuals if we (those in power in engineering and engineering education) realize we how closely we are connected to the structures and norms which originally and continuously locked the building towards exclusion.

\section{Further Work to Contextualize Present-Day Engineering}

This historical context can be seen as a starting point, and there are limitations of the historical account I have presented, which can and should be developed further. For example, the story of gender exclusion focused more heavily on culture than did the story of racial exclusion. If the account of gender is indicative, racial normativities (the norms of whiteness) must play a role in the perpetuating of engineering cultural norms. This is an area for further conversation and suggests the utility of incorporating critical whiteness theories in engineering educational settings (Battey \& Leyva, 2016).

Historical context will be critical to informing my own (and others') ongoing education research, which relies heavily on context to interpret a setting, including that which is and is not being said in a given scene. In further work I intend to revisit my ethnographic data on classroom interactions which are embedded inside engineering educational cultural norms to look for ways in which the historical context shapes present-day interactions constructing marginalization. I particularly hope to take up critical masculinity and critical whiteness lenses, while seeing identity norms as intertwined with disciplinary practices and narratives. The broader goal of this research effort is to understand educational culture in order to shift marginalizing classroom practices. 
Finally in this historical account, I presented certain cultural norms (whiteness, masculinity, competition) as potential culprits to examine for their impact on engineering practices, norms, and demographic representation. Undoubtedly, there are more. Those of us aware of this context can continue to ask ourselves: what are the fingerprints of history on the culture of engineering? 


\section{References:}

Alexander, M. (2010). The New Jim Crow: Mass Incarceration in the Age of Colorblindness. New York, NY: The New Press.

ASEE Task Force. (1987). A national action agenda for engineering education. Washington, D.C.

Baptist, E. (2014). The half has never been told: Slavery and the making of American capitalism. Basic Books.

Battey, D., \& Leyva, L. A. (2016). Whiteness in Mathematics Education. Journal Urban Mathematics Education, 9(2), 49-80.

Bird, S. R. (2016). Welcome to the Men's Club: Homosociality and the Maintenance of Hegemonic Masculinity Stable. Gender \& Society, 10(2), 120-132.

Bix, A. S. (2000). "Engineeresses" Invade Campus: Four decades of debate over technical coeducation. IEEE, Technology and Society Magazine, 19(1), 20-26.

Bix, A. S. (2002). Equipped for Life: Gendered Technical Training and Consumerism in Home Economics, 1920-1980. Technology and Culture, 43(4), 728-754. http://doi.org/10.1353/tech.2002.0152

Bix, A. S. (2004). From "Engineeresses" to "Girl Engineers" to "Good Engineers": A History of Women's U.S. Engineering Education. NWSA Journal, 16(1), 27-49.

Blackmon, D. A. (2009). Slavery by another name: The re-enslavement of black Americans from the Civil War to World War II. Anchor.

Crawley, E. F., Malmqvist, J., Östlund, S., \& Brodeur, D. R. (2014). Rethinking Engineering Education. http://doi.org/10.1007/978-3-319-05561-9

Danielak, B. A., Gupta, A., \& Elby, A. (2014). Marginalized Identities of Sense-Makers : Reframing Engineering Student Retention. Journal of Engineering Education, 103(1), 8-44. http://doi.org/10.1002/jee.20035

Deboer, G. E. (1991). A History of Ideas in Science Education: Implications for Practice. New York, NY: Teachers College Press.

Dutson, A. J., Todd, R. H., Magleby, S. P., \& Sorensen, C. D. (1997). A Review of Literature on Teaching Engineering Design Through Project-Oriented Capstone Courses. Journal of Engineering ..., (January).

Ensmenger, N. (2010). Making Programming Masculine. Gender Codes: Why Women Are Leaving Computing, 115-141. http://doi.org/10.1002/9780470619926.ch6 
Foor, C. E., Walden, S. E., \& Trytten, D. a. (2007). "I wish that I belonged more in this whole engineering group:" Achieving individual diversity. Journal of Engineering Education, (April), 103-115. http://doi.org/10.1002/j.2168-9830.2007.tb00921.x

Foucault, M. (1977). Nietzsche, genealogy, history. In D. F. Bouchard \& S. Simon. (Eds.), Language, counter-memory, practice: Selected essays and interviews. Ithaca, NY: Cornell University Press.

Foucault, M. (1982). The Subject and Power. Critical Inquiry, 8(4), 777-795. http://doi.org/10.1086/448181

Frehill, L. (2004). The Gendered Construction of the Engineering Profession in the United States, 1893-1920. Men and Masculinities, 6(4), 383-403. http://doi.org/10.1177/1097184X03260963

Frey, D. D., Smith, M., \& Bellinger, S. (2000). Using Hands-On Design Challenges in a Product Development Master’s Degree Program. Journal of Engineering Education, (October).

Hughes, R. (2012). Gender Conception and the Chilly Road To Female Undergraduates' Persistence in Science and Engineering Fields. Journal of Women and Minorities in Science and Engineering, 18(3), 215-234. http://doi.org/10.1615/JWomenMinorScienEng.2013003752

Kirchgasler, K. L. (2016). The Making of Nonscientists and Not-Yet-Citizens: Historicizing the Racialization of U.S. Science Education. In American Educational Research Association Annual Meeting. Washington, D.C.

Klein, J. (1996). Crossing boundaries: Knowledge, disciplinarities, and interdisciplinarities. University of Virginia Press.

Kohn, A. (1992). No Contest: The Case Against Competition. Houghton Miller Harcourt.

Lipman-Blumen, J. (2016). Toward a Homosocial Theory of Sex Roles: An Explanation of the Sex Segregation of Social Institutions. Signs, 1(3, Women and the Workplace: The Implications of Occupational Segregation), 15-31.

Lucena, J. (2000). Making Women and Minorities in Science and Enginering. Journal of Women and Minorities in Science and Engineering, 6(1), 1-31.

Lucena, J. (2005). Defending the nation: US policymaking to create scientists and engineers from Sputnik to the "War against Terrorism.” University Press of America.

McDermott, R., \& Varenne, H. (1995). Culture “as" Disability. Anthropology \& Education Quarterly, 26(3), 324-348.

Myers, M. A., \& Massey, J. L. (1991). Race, Labor, and Punishment in Postbellum Georgia. Social Problems, 38(2), 267-286. 
National Academy of Engineering. (2004). The Engineer of 2020: Visions of Engineering in the New Century. Washington, D.C.: The National Academies Press.

National Science Foundation. (2013). National Center for Science and Engineering Statistics, Scientists and Engineers Statistical Data System (SESTAT).

Noble, D. (1992). A World Without Women: The Christian Clerical Culture of Western Science. New York, NY: Knopf.

O’Connor, K., Peck, F. A., Cafarella, J., \& McWilliams, J. (2016). Working in the weeds: How do instructors sort engineering students from non-engineering students in a first-year PreCalculus course? In American Society for Engineering Education Annual Conference. New Orleans, LA.

Oldenziel, R. (1999). Making Technology Masculine. Amsterdam: Amsterdam University Press. http://doi.org/10.1017/CBO9781107415324.004

Oldenziel, R. (2000). Multiple-Entry Visas: Gender and Engineering in the US, 1870-1945. In A. Canel, R. Oldenziel, \& K. Zachmann (Eds.), Crossing Boundaries, Building Bridges: Comparing the History of Women Engineers 1870s - 1990s. Amsterdam: Harwood Academic Publishers.

Oldenziel, R. (2006). Introduction: Signifying Semantics for a History of Technology. Technology and Culture, 47(3), 477-485.

Pawley, A. L. (2008). What Counts as "Engineering": Toward a Redefinition. In D. M. Riley, A. L. Pawley, \& C. Baillie (Eds.), Engineering and Social Justice (pp. 59-85). West Lafayette, IN: Purdue University Press.

Prince, M. (2004). Does Active Learning Work? A Review of the Research. Journal of Engineering Education, 93(3), 223-231. http://doi.org/10.1002/j.2168-9830.2004.tb00809.x

Roediger, D. R. (2007). The Wages of Whiteness: Race and the Making of the American Working Class. London, UK: Verso.

Secules, S., Gupta, A., \& Elby, A. (2016). "Turning away" from the Struggling Individual Student: An Account of the Cultural Construction of Engineering Ability in an Undergraduate Programming Class. In American Society for Engineering Education Annual Conference. New Orleans, LA.

Seely, B. E. (1999). The Other Re-engineering of Engineering Education, 1900-1965. Journal of Engineering Education, (July), 285-294.

Seymour, E., \& Hewitt, N. M. (2000). Talking About Leaving: Why undergraduates leave the sciences. Boulder, CO: Westview Press.

Slaton, A. E. (2010a). Engineering Segregation: The University of Maryland in the Twilight of Jim Crow, 24(July), 15-24. 
Slaton, A. E. (2010b). Race, rigor, and selectivity in US engineering: The history of an occupational color line. Cambridge, MA: Harvard University Press.

Slaton, A. E. (2015). Meritocracy, Technocracy, Democracy: Understandings of Racial and Gender Equity in American Engineering Education. In International Perspectives on Engineering Education. http://doi.org/10.1007/978-3-319-02904-7

Stevens, R., Amos, D., Jocuns, A., \& Garrison, L. (2007). Engineering as Lifestyle and a Meritocracy of Difficulty: Two Pervasive Beliefs Among Engineering Students and Their Possible Effects. In American Society for Engineering Education Annual Conference.

Stevens, R., O’Connor, K., Garrison, L., Jocuns, A., \& Amo, D. M. (2008). Becoming an Engineer: Toward a Three Dimensional View of Engineering Learning. Journal of Engineering Education, 97(3), 355-368. http://doi.org/10.1002/j.2168-9830.2008.tb00984.x

Todd, R. H., Sorensen, C. D., \& Magleby, S. P. (1993). Designing a Senior Capstone Course to Satisfy Industrial Customers. Reprinted from Journal of Engineering Education, 82(2).

Tonso, K. L. (1996). Student learning and gender. Journal of Engineering Education, (April).

Tonso, K. L. (2006). Teams that Work: Campus Culture, Engineering identity, and Social Interactions. Journal of Engineering Education, 95(1), 25-37. http://doi.org/10.1002/j.21689830.2006.tb00875.x

Varenne, H., \& McDermott, R. (1999). Successful Failure: The School America Builds. Boulder, CO: Westview Press.

Wajcman, J. (1991). Feminism Confronts Technology. Cambridge, UK: Polity Press.

Wajcman, J. (2006). Technocapitalism meets technofeminism: women and technology in a wireless world. Labour \& Industry, 16(3), 7-20. http://doi.org/10.1080/10301763.2006.10669327

Wharton, D. E. (1992). A Struggle Worthy of Note: The Engineering and Technological Education of Black Americans. Westport, CT: Greenwood Press.

Williams, E. (1964). Capitalism and Slavery. London, UK: Andre Deutsch Limited.

Wisnioski, M. (2014). "Suppose the World were Already Lost": Worst Case scenario and the engineering imagination at Harvey mudd college. Engineering Studies. http://doi.org/http://dx.doi.org/10.1080/19378629.2014.931407

Zussman, R. (1985). Mechanics of the middle class: Work and politics among American engineers. University of California Press. 